\title{
PRESSURE RELIEF AND EXTENSIONAL FRACTURES ALONG THE LITHOSPHERIC- ASTENOSPHERIC DECOUPLING: IMPLICATIONS FOR MAGMA GENERATION
}

H.H.G.J.Ulbrich

A given rock will undergo partial melting as soon as the temperature is raised above its solidus curve, for the given composition and pressure. This is a truism, but it is still difficult to propose structural (more than physical) mechanisms that control melting in a normally solid rock. At destructive plate margins, the accepted structural model is that of subduction, which moves water and other materials into deeper levels, thus destabilizing formerly "dry" peridotites and generating, directly and indirectly, assorted types of magmas. This answer is not applicable for basaltic volcanoes erupting within oceanic plates. The emplacement of some of the larger occurrences can be explained by a hotspot mechanism (e.g., Hawaii). How about the others?

It is here proposed that movement along the lithospheric-astenospheric decoupling zone (LADZ) creates a stress regime that is able to open up extensional fractures (EF), both above and below the LADZ. If the LADZ is interpreted as a shear surface, then the upper EF will lie, in the more rigid lithosphere, at a steeper angle to this zone, while the other EF, in the plastic astenosphere, show a flatter angular relationship. The main point about EF is that they will be wetted by incoming fluids, according to the "hydrothermal pumping" model proposed by SIBSON et al. (1975; Jl.Geol.Soc.Lond., 131:653-659), in another context. The common model for the upper astenosphere ( $\left.>1300^{\circ} \mathrm{C}\right)$, is that of ductile rocks with minor amounts of melt. The structural model that emerges here is that of a hot mantle cut by (possibly very closely spaced) EF; within these fractures, most of the melting will occur. Basaltic magmas may thus continuously be generated, above and below the LADZ, erupting in the oceanic plate.

There is no reason to apply this mechanism only to oceanic LADZ. The "basaltic

Departamento de Mineralogia e Petrologia, Instituto de Geociências, USP. 
magma underplating" of continental crust calls for hot magmas that spread out under the lower crust and may provide the heat source that melts crustal rocks. These magmas may well come from EF above and below the LADZ overlain by continents.

Generation of continental "anorogenic" alkaline magmas is usually linked to the appearence of tensional regimes; in some cases (e.g., Bolivia's Velasco massif), a hot spot piercing a continent may be the cause. A general mechanism of pressure relief can be envisaged, controlled by plate movement along an irregular LADZ. An example illustrates. A saucer-shaped LADZ is depicted, along a E-W section. The zone is horizontal (to the E), then dips downwards, resumes horizontality (thickened lithosphere), dips upwards and regains horizontal attitude (to the $W$ ). A lithosphere moving $E$ to $W$ will create pressure-relief areas along, and nearby, both dipping discontinulties (with different geometries), similarly to the "voids", filled with ore, formed by movement along Z-shaped faults. Positions of relief areas will vary, according to model (e.g., dome-shaped LADZ, equivalent to an upside-down saucer-shaped LADZ). A model such as this may explain the systematic concentration of alkaline occurrences at the margins of basins, as in the Paraná Basin. 